\title{
Análise comparativa dos custos de produção de suínos sob a ótica da teoria contratual
}

Leandro Augusto Toigo
Doutorado em andamento em Administração e Ciências Contábeis pela Universidade
Regional de Blumenau - FURB
Rua Antônio da Veiga, 140. Blumenau/SC. CEP: 89012-900
E-mail: leandrotoigo@yahoo.com.br

Vanderlei Gollo

Mestrado em Ciências Contábeis pela Universidade Regional de Blumenau - FURB Rua Antônio da Veiga, 140. Blumenau/SC. CEP: 89012-900

E-mail:vande_gollo@hotmail.com

Maurício Leite

Mestrado em Ciências Contábeis pela Universidade Regional de Blumenau - FURB Rua Antônio da Veiga, 140. Blumenau/SC. CEP: 89012-900

E-mail:mauricio.leite@ymail.com

Roberto Carlos Klann Doutorado em Ciências Contábeis e Administração pela Universidade Regional de Blumenau - FURB Rua Antônio da Veiga, 140. Blumenau/SC. CEP: 89012-900

E-mail: rklann@furb.br

\section{RESUMO}

Esse estudo tem o objetivo de analisar os custos das diferentes modalidades de produção na suinocultura catarinense. Para tanto, foram utilizados dados sobre os custos da suinocultura de Santa Catarina referentes ao ano de 2013 divulgados pela Companhia Nacional de Abastecimento CONAB, que é uma agência que disponibiliza informações seguras e atualizadas. Foram identificados os cenários da suinocultura, considerando que algumas modalidades de produção podem ser divididas em dois cenários, um em que o suinocultor atua com recursos próprios ou de forma independente e outro sob contrato de comodato firmado com uma empresa integradora. Foi realizada uma análise trimestral e uma geral para o período. Os resultados apontam para menores custos de produção quando há a existência de contratos de comodato. As demonstrações dos cenários indicam custos mais elevados na modalidade de ciclo completo, mesmo com período menor para desenvolvimento e com peso final dos suínos menor. Conclui-se, portanto, que os constantes crescimentos das modalidades de produção sob os modelos de comodato justificam-se devido aos menores custos de produção.

Palavras-chave: Sistemas de produção de suínos. Contratos de comodato. Produção independente. 


\section{Comparative analysis of pig production costs from the perspective of contract} theory

\section{ABSTRACT}

This paper aims to analyze the costs of the different modes of production in Santa Catarina swine. For this, we used data on the costs of swine Santa Catarina for the year 2013 released by the National Supply Company CONAB, which is an agency that offers secure and updated information. Scenarios swine were identified, whereas some production methods can be divided into two scenarios, one in which the swine producer works with own resources or independently and under other lending agreement with an integrative company. A quarterly analysis and a general was conducted for the period. The results point to lower production costs when there is the existence of lending agreements. The statements of scenarios indicate higher costs in full cycle mode, even less time for development and final weight of the smallest pigs. It follows, therefore, that the steady growth in terms of production under the lending models are justified due to lower production costs

Keywords: Swine production systems. Lease agreements. Independent production.

\section{INTRODUÇÃO}

O ambiente externo e econômico, o segmento em que as organizações estão inseridas, assim como as suas principais escolhas, cada vez mais, são fatores críticos de sucesso das sociedades e dos sistemas produtivos. Com isso, de maneira mais acentuada, as organizações passam a necessitar de conhecimento e práticas capazes de orientar suas estratégias com o fim de assegurar a sua continuidade.

O "advento da competitividade global acelerada, reduzido ciclos de produtos, rápidos avanços tecnológicos, organizacionais e entre cadeias tem aumentado drasticamente a necessidade de abordagens mais eficazes de gestão dos custos" (LOCKAMY III, 2003, p. 1). Shank e Govindarajan (1997, p. 59) assinalam que "[...] gerenciar custos eficazmente exige um enfoque amplo, externo à empresa [...]". Informações e práticas de custos devem ser utilizadas com esse enfoque, em que acontecimentos externos à companhia também podem afetá-la e por isso devem ser considerados durante a gestão dos custos e elaboração das estratégias. 
Para atender as necessidades de adaptação das organizações em um contexto de busca por melhoria contínua da competitividade, surgiu a Gestão Estratégica de Custos - GEC (SHANK; GOVINDARAJAN, 1997). Os autores explicam que os dados de custos são utilizados para desenvolver estratégias superiores a fim de se obter uma vantagem competitiva sustentável. Esse tema vem sendo pesquisado por Porter (1989), Shank; Govindarajan (1997), Cooper; Slagmulder (1998), Aguiar; Rocha (1999), Rocha (1999), Lockamy III (2003), Anand (2004), Diehl (2004), Anderson (2006), Ellram (2006), El-Kelety (2006), El-Dyasty (2007), Souza; Rocha (2008), Wrubel (2009) e Wrubel et al. (2011).

Shank e Govindarajan (1997) mencionam algumas práticas GEC, tais como: custeio $A B C$, análise de cadeia de valor, dos custos da qualidade e dos direcionadores de custos. A GEC torna-se um importante referencial para a tomada de decisões na gestão estratégica porque envolve acontecimentos externos a empresa, mas que impactam nas suas operações e nos seus custos. Nesse caso, atenta-se para a seguinte situação: os fornecedores não produzem e entregam apenas insumos que serão utilizados nas atividades de valor de uma empresa, mas influenciam de modo importante os custos e posição de custos/diferenciação da empresa (PORTER, 1989; SHANK; GOVINDARAJAN, 1997).

Segundo Sornberger e Nantes (2011), em âmbito mundial a GEC da suinocultura é considerada relevante pois em 2009 apresentou uma produção e consumo de 100 milhões de toneladas apresentando tendência de crescimento. Os autores abordam também que, no Brasil a suinocultura evoluiu significativamente nos últimos anos, em suas técnicas de produção e modelo organizacional com seus fornecedores de insumos, atacado, varejo e consumidores em geral, sendo que, as agroindústrias ou frigoríficos no papel de integradoras foram os grandes fomentadores deste desenvolvimento.

Miele (2006) explica que a produção de suínos brasileira faz uso de intensivos fatores de produção, com ganhos de escala cada vez maiores explorando estratégias da especialização, tendo granjas núcleos que produzem apenas reprodutores (machos, 
fêmeas e sêmen), e outras granjas que fazem Ciclo Completo (CC), também existem as granjas que unicamente produzem leitões (UPL), e granjas que apenas fazem somente a terminação de suínos (UT). Key e McBride (2003) e Weydmann, assim como Conceição (2003) abordam que a especialização ocorre em vários países do mundo, inclusive nos Estados Unidos, e a redução da quantidade de suinocultores em ciclo completo, e crescente a adoção das granjas com especialização em UPL e UT. Dessa forma, identifica-se claramente os elos da cadeia de valor representam maior nível de conhecimento técnico sobre a atividade suinícola. Sobre esta cadeia de valor observase a atuação parcial de agroindústrias, que fomentam os criadores com insumos produtivos por meio da integração vertical, que por sua vez, criam uma relação contratual de mercado devidamente formalizada.

A pesquisa da teoria dos contratos das firmas na agricultura, tal como enfocada por Heady E Dillon (1961), exerce influência na academia, particularmente a partir da ótica da função de produção. Sendo que isso, gerou relevante volume de pesquisas empíricas focalizada no papel dos preços e na alocação eficiente dos recursos. Uma organização consolida-se por um conjunto de contratos entre as partes envolvidas no negócio (fornecedores, clientes, investidores, governo, funcionários, etc.) que se relacionam trocando ativos e informação (DALMÁCIO; REZENDE, 2008). McDonald et al. (2004) aborda que um estudo conduzido pelo USDA (Departamento de agricultura Norte-americano) indica que a adoção de contratos é mais frequente nos produtores de maior escala produtiva, e que os mesmos preferem os contratos à comercializar via mercados, destacando as razões como a redução de riscos e a economia de custos de transação como as mais relevantes.

Os aspectos mencionados instigam a realização dessa pesquisa, visando responder a seguinte questão: Qual é o comportamento dos custos de produção na suinocultura sob a ótica da Teoria contratual da firma? O objetivo do estudo é analisar os custos das diferentes modalidades e cenários de produção da suinocultura catarinense. 
A justificativa para a realização deste estudo reside no fato que a maioria das granjas de produção de suínos ou empresas agrícolas utilizam quantidade reduzida de ferramentas gerenciais em suas atividades produzidas, e quando são utilizadas, não são utilizadas de forma adequada pelos suinocultores (NOGUEIRA, 2004). Busca-se também, com os resultados, contribuir com estudos anteriores relacionados com a teoria contratual da firma e a gestão estratégica de custos. Outro ponto importante é que a adoção de ferramentas gerenciais por parte do suinocultor pode proporcionar-Ihe a aferição de maiores resultados financeiros, fortalecendo sua permanência no negócio.

\section{REFERENCIAL TEÓRICO}

Nesta revisão de literatura são abordados temas que embasam conceitualmente a problemática da pesquisa em questão. Inicialmente são apresentadas informações acerca da Teoria Contratual da Firma, seguido da gestão estratégica de custos, que é o interesse da pesquisa, finalizando com a discussão acerca da suinocultura.

\subsection{Teoria contratual da firma}

Coase (1937) em seu mais conhecido artigo "The NatureoftheFirm" e posteriormente complementado no artigo "The Problemof Social Cost" de 1960, discute as organizações e as razões para a existência da firma baseado nos custos comparativos da organização interna e de produção via mercado, e lançou as bases para o estudo das formas alternativas de organização das firmas contratuais. Ele percebeu que os mercados não funcionam a custo zero. Seus questionamentos chamaram a atenção para os fenômenos do mundo real e para o rico laboratório vivo do mundo das organizações, que estavam à espera de estudo cuidadoso. Sua crítica em relação a visão da firma como função de produção, sugerindo não ter aderência ao mundo real escrito no início da sua carreira, só teve o impacto pleno a partir da década de 1970. 
Zylbrsztajn (2005), aponta que as indagações de Coase e a teoria que dela partiu, abriram caminho para a análise da organização interna das firmas e das relações entre elas, seja no suprimento de matérias primas ou na distribuição dos seus produtos. Existem custos associados ao funcionamento dos mercados que podem exceder os custos da organização interna. Assim, a firma apresentada por Coase tem natureza contratual, e aparece como uma resposta eficiente dos agentes econômicos para coordenar a produção. A existência de custos para realizar as transações, o que não elimina a possibilidade da sua condução via mercado e portanto, o sistema de preços continua sendo relevante, podendo funcionar como mecanismo eficiente de recursos.

Para Tigre (1998), o ponto de vista institucional da organização interna da firma foi observado de forma gradual e fragmentada, refletindo a grande complexidade que a observação das empresas apresenta na prática. As indagações sobre a natureza de seu crescimento, objetivos e formas de organização dependeram não apenas de observações empíricas, mas também da acumulação de conhecimentos que deram origem a novos conceitos. $O$ aporte de teorias oriundas de outras áreas do conhecimento, a exemplo da biologia evolucionista, da psicologia cognitiva e da administração de empresas, permite incorporar dimensões mais sutis e mais difíceis de serem captadas e incorporadas pelas teorias econômicas convencionais. A ortodoxia metodológica da teoria neoclássica limitou a percepção de questões complexas diante da própria limitação de seus instrumentos e variáveis de análise.

Adicionalmente, a teoria da firma focaliza apenas a produção com o propósito de maximização de lucros, deixando à margem o estudo de outras formas de organização, como as organizações sem fins lucrativos, as firmas políticas e as associações e entidades de representações. Talvez o distanciamento entre a teoria da firma e a firma observada no mundo real tenha sido a causa de tanto desestímulo aos alunos, especialmente de graduação, que se desencantam com as disciplinas introdutórias de microeconomias (ZYLBRSZTAJN; 2005). 
Para Lopes (2012), a chamada Teoria Contratual da Firma, sob o ponto de vista teórico, caracteriza empresa como sendo um conjunto de contratos entre diversos participantes. Cada participante contribui com algo para a firma e em troca recebe sua parte no bolo. Empregados contribuem com a força de trabalho e recebem, em troca salários. Os acionistas contribuem com capital e recebem dividendos e ganhos deste capital investido. Fornecedores contribuem com produtos e serviços e recebem dinheiro. O governo contribui garantindo a estabilidade institucional e para isso recebe os impostos. Os contratos são de diversas naturezas, dependendo da relação entre os interessados.

Ainda segundo Lopes (2012), o funcionamento adequado da empresa depende do equilíbrio contratual estabelecido. Se uma das partes não está satisfeita com os termos de seu contrato, ou com sua execução, as atividades da empresa podem ser prejudicadas ou até mesmo interrompidas. É imprescindível que os contratos sejam exercidos da forma mais harmônica possível. No entanto, na prática surgem alguns problemas em relação a execução e imposição dos contratos, tais como informações imperfeitas que tratam do conhecimento das regras entre as partes envolvidas, mas não de suas ações individuais, e da informação incompleta na qual nem as informações nem as ações individuais são de conhecimento mútuo. Esses problemas podem levar ao colapso total das atividades da empresa.

Para Zylbrsztajn (2005), a economia aplicada à agricultura tem seu desenvolvimento relacionado à teoria da firma, em que pese a relevância dos temas macroeconômicos. Os estudos das relações de produção, sempre tiveram destaque na pesquisa e ensino no campo aplicado da Economia Agrícola. Embora os estudos da firma como função de produção tenham caído em desuso, as aplicações empíricas da teoria da produção ao estudo da economia agrícola foram, e ainda são direcionadas ao estudo do funcionamento dos mercados e suas derivações. Políticas de preço, impactos de distorções do funcionamento livre do mercado são a tônica da tradicional teoria, seja sob a ótica da firma, ou sob a ótica da demanda, que permite, a partir dos 
pressupostos dos mercados perfeitos, estudar os impactos de políticas públicas e intervenções de diferentes naturezas.

\subsection{Gestão estratégica de custos}

Os temas relacionados à gestão estratégica de custos (GEC) têm sido debatidos nos últimos anos, o que gerou pesquisas como as de Cooper; Slagmulder (1999, 2003, 2004); Bacic (1994); Shank; Govindarajan (1997); Fu (2007); além discussões sobre práticas: custeio baseado em atividades abordado por Nakagawa (1994), entre outras. Ellram; Siferd (1993) tratam sobre o custo total de propriedade, Ellram (2006) sobre custo-meta e Diehl (1997) propôs método de avaliação dos custos intangíveis.

"O sistema de gestão de custos da empresa deve ser mais dinâmico para lidar com a mais rápida mudança no ambiente e com a crescente diversidade de produtos e processos de fabricação" (EL KELETY, 2006, p. 2-3). A GEC, para Cooper e Slagmulder (1998, p. 14), é a "aplicação das técnicas de gestão de custos de maneira que, simultaneamente, melhore a posição estratégica de uma empresa e reduza seus custos". Para atender seus propósitos a Gestão Estratégica de Custos se baseia em três temas-chave, conforme abordagem de Shank e Govindarajan (1997, p. 8): “(1) Análise da cadeia de valor; (2) Análise do posicionamento estratégico; (3) Análise dos direcionadores de custos", para então, abordar sobre a suinocultura brasileira.

A cadeia de valor torna-se um importante referencial para a tomada de decisões na gestão estratégica porque envolve acontecimentos externos a empresa, mas que impactam nas suas operações e nos seus custos. Nesse caso, atenta-se para a seguinte situação: os fornecedores não produzem e entregam apenas insumos que serão utilizados nas atividades de valor de uma empresa, mas influenciam de modo importante os custos e posição de custos/diferenciação da empresa (PORTER, 1989; SHANK; GOVINDARAJAN, 1997).

Porter (1989, p. 47) exemplifica a influência nos custos, mencionando que: 
Remessas frequentes do fornecedor podem reduzir as necessidades de estoque de uma empresa, uma embalagem apropriada dos produtos do fornecedor pode reduzir o custo de manuseio, e a inspeção feita pelo fornecedor pode eliminar a necessidade de inspeção de chegada pela empresa.

Para que a empresa atinja seus objetivos não é suficiente que visualize apenas as operações internas, isoladamente, embora isso seja útil para integrar todas as funções, atividades e tarefas (BOWERSOX; CLOSS, 1996). É necessário, segundo os autores, que essas empresas estendam seu comportamento para incorporar clientes e fornecedores, por meio da integração externa, por eles denominada gestão estratégica de custos.

\subsection{Suinocultura brasileira}

O desenvolvimento da suinocultura ocorreu de forma significativa nos últimos anos, tanto no Brasil como no mundo todo. De acordo com a Associação Catarinense de Criadores de Suínos (ACCS, 2008), com a carne cada vez mais saborosa, saudável e segura, a suinocultura vem ajudando a construir o desenvolvimento econômico e social de várias regiões do país, proporcionando emprego e renda a milhares de brasileiros.

Dados do Ministério da Agricultura, Pecuária e Abastecimento (MAPA) indicam que o Brasil está em quarto lugar no ranking de produção e exportação mundial de carne suína, devido a estudos e investimentos feitos nesta atividade. Entre os fatores que contribuíram para esta posição de destaque do país, estão alguns elementos como sanidade, nutrição, bom manejo das granjas, produção integrada e, principalmente, aprimoramento gerencial dos produtores (MAPA, 2012).

A suinocultura é responsável pela sustentação de diversos setores econômicos, pois além da geração de empregos e renda à população, a atividade suinícola sustenta parte do agronegócio brasileiro por meio das indústrias e das exportações das carnes suínas (ZANIN; BAGATINI; PESSATTO, 2010). 
Esta atividade cresce no Brasil em torno de $4 \%$ ao ano, destacando-se nos estados de Santa Catarina, Paraná e Rio Grande do Sul, onde estão os principais produtores de suínos do país. O Brasil é responsável por $10 \%$ do volume mundial das exportações de carne suína, chegando a lucrar mais de US\$ 1 bilhão por ano. Há estimativa para um crescimento anual médio na produção e consumo, no período de 2008/2009 a 2018/2019, de 2,84\% e 1,79\%, respectivamente. Para as exportações, o mercado brasileiro de carne suína poderá saltar de 10,1\% em 2008 para 21\% em 2018/2019 (MAPA, 2012).

Fontes da Secretaria de Estado da Agricultura e do Abastecimento (SEAB) indicam que a suinocultura no Brasil é desenvolvida principalmente de forma integrada à indústria, sendo que os produtores independentes representam menos de $25 \%$ da produção total. Em termos de produção, destaque para a região sul, que é responsável por quase $50 \%$ da produção nacional (SEAB, 2013).

Segundo Miele e Machado (2010), a carne suína brasileira é processada por dois distintos grupos de empresas: as líderes de mercado e as que atuam em mercados regionais e globais. Entre as líderes de mercado predomina a busca por ganhos de escala, a promoção da marca em produtos processados e a integração da produção. São organizações de grande porte, com mais de uma unidade industrial e abrangência internacional, sendo que a maioria destas empresas processa não somente carne suína, mas também de outras espécies.

O mercado da suinocultura sofre com constantes oscilações no preço dos suínos, bem como no custo dos insumos utilizados na produção. Conforme Lopes (2013), entre estes períodos inconstantes pode-se destacar o ano de 2012, que apresentou um dos piores anos para os produtores de suínos, com preços muito baixos pagos aos suinocultores, ao mesmo tempo em que as cotações de milho e farelo de soja extrapolaram todos os recordes nacionais e internacionais, elevando o custo de produção a patamares nunca vistos. 
Roppa (2012) destaca que uma crise em decorrência desses mesmos fatores, baixos preços de venda e altos custos de produção, afetaram fortemente a suinocultura em 2002. Na época os custos de produção superaram o preço de venda, fazendo com que muitos criadores acumulassem grandes prejuízos e, em decorrência disso, precisaram largar a atividade. $O$ autor ressalta que em dois anos foram abatidas 360 mil matrizes, constituindo a maior destruição de capital genético da história da pecuária brasileira.

Pela abordagem de Lopes (2013) e Roppa (2012), percebe-se que a suinocultura passa por momentos de crises econômicas que reduzem as margens de lucro na atividade, assim as granjas de produção tem mudado sua forma de desenvolvimento nos últimos anos, saindo da modalidade de produção independente para modelos de contrato de comodato, passando a produzir em grande escala para manterem-se atuando e produzindo animais. Os impactos dessas mudanças na forma de produção podem ser evidenciados a partir das informações contábeis produzidas pelas organizações inseridas nesta cadeia produtiva.

\section{PROCEDIMENTOS METODOLÓGICOS}

O presente estudo caracteriza-se como descritivo quanto ao seu objetivo, como documental em relação aos procedimentos e análise com abordagem quantitativa quanto ao problema proposto. Para tanto, foram utilizados dados sobre os custos da suinocultura no estado de Santa Catarina, referentes ao ano de 2013. Os referidos dados estão publicados pela CONAB - Companhia Nacional de Abastecimento.

Para a realização da análise foram utilizadas as informações disponibilizadas pela CONAB (2013), em cada uma das modalidades da produção de suínos, bem como a forma de contrato para o desenvolvimento da atividade. Com as informações foram elaborados os possíveis cenários para a atividade da suinocultura. As modalidades ou etapas que compreendem a atividade da suinocultura encontram-se apresentadas no Quadro 1. 
Análise comparativa dos custos de produção de suínos sob a ótica da teoria contratual Leandro Augusto Toigo, Vanderlei Gollo, Maurício Leite, Roberto Carlos Klann

\begin{tabular}{|c|c|}
\hline Modalidade/Etapa & Descrição \\
\hline UPLD & Unidade produtora de leitões desmamados sem contrato \\
\hline UPLD Comodato & Unidade produtora de leitões desmamados com contrato de comodato \\
\hline UPLC Comodato & Unidade produtora de leitões em crechário com contrato de comodato \\
\hline UPL & Unidade produtora de leitões \\
\hline UPL Comodato & Unidade produtora de leitões com contrato de comodato \\
\hline UT Comodato & Unidade de terminação com contrato de comodato \\
\hline Ciclo Completo & Unidade de produção de suínos ciclo completo sem contrato \\
\hline
\end{tabular}

Quadro 1: Etapas e modelos da suinocultura

Fonte: Dados da pesquisa.

A análise para o período de 2013 deve-se ao fato de que apenas os dados de 2013 estão disponíveis de forma detalhada e nas diferentes modalidades da atividade de criação de suínos. Tendo em vista que os dados referentes aos custos estão disponíveis de forma mensal, optou-se por fazer a análise trimestralmente, a fim de acompanhar o seu comportamento ao longo do ano.

A partir das informações encontradas sobre as diferentes modalidades de produção de suínos, foram elaborados os possíveis cenários, que são subdivisões das modalidades de produção da cadeia de suínos, para encontrar os custos em cada um deles. Com isso, foi possível analisar o seu comportamento da produção de suínos entre as modalidades e cenários.

\section{ANÁLISE DOS RESULTADOS}

Com o objetivo de apresentar o comportamento dos custos da suinocultura catarinense para o ano de 2013, buscou-se inicialmente apresentar uma ilustração demonstrando as modalidades e cenários que compreendem o desenvolvimento da atividade suinícola. Os cenários são identificados no campo, os quais as informações foram encontradas junto ao sítio da CONAB (2013), estão demonstrados na Figura 1. 


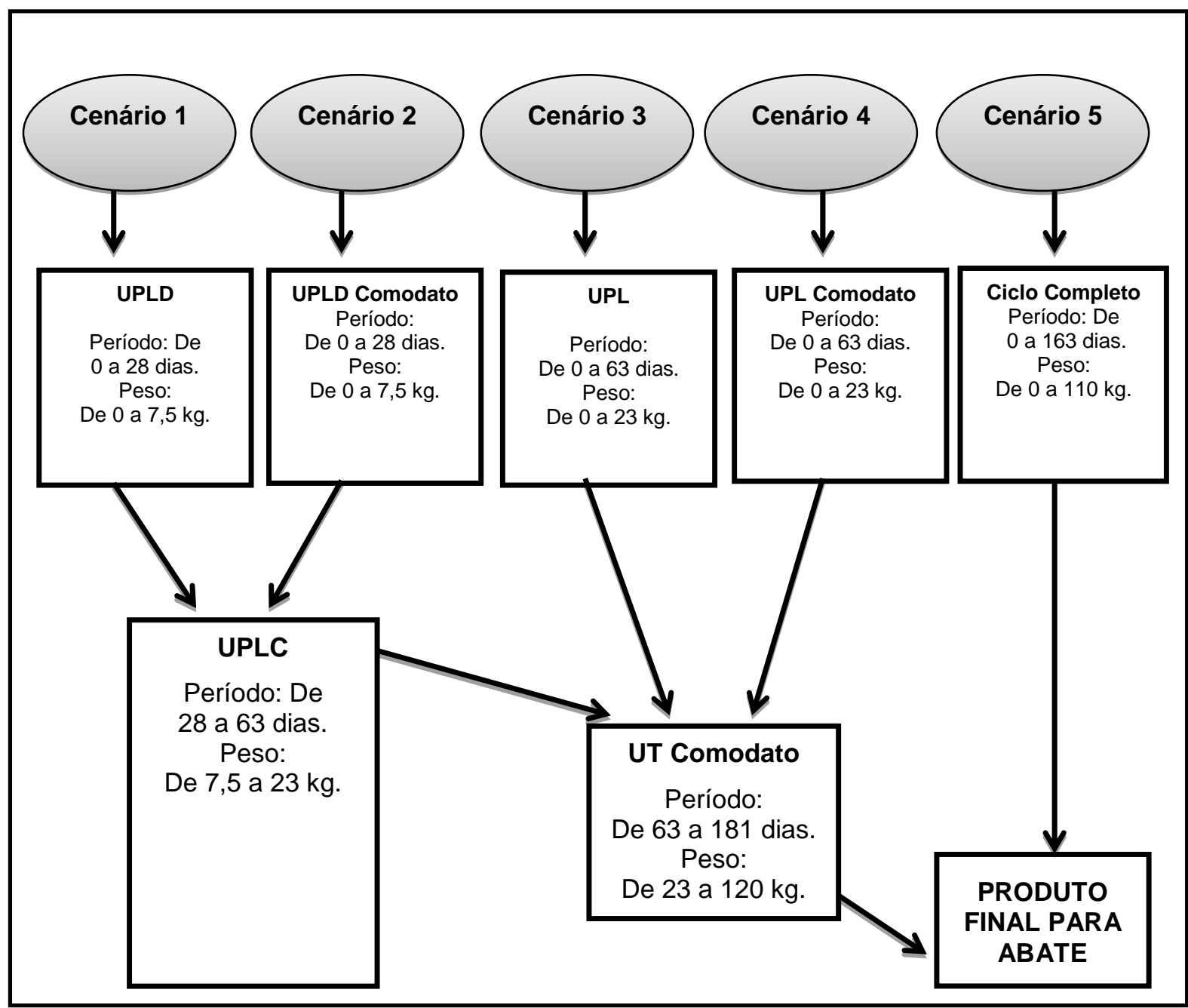

Figura 1: llustração das modalidades produtivas da suinocultura

Fonte: Elaborado pelos autores

Pela ilustração apresentada na Figura 1, é possível identificar quais são as possíveis modalidades no desenvolvimento da suinocultura, bem como os modelos de contratos existentes entre as diferentes modalidades de produção de suínos (cenários das modalidades). Para efeitos desta análise, os valores apresentados em relação ao peso e quantidade de dias de cada modalidade obedecem a uma média informada pela CONAB conforme o cenário da suinocultura catarinense.

Quando há contratos de comodato na modalidade, significa que a empresa é responsável pelos animais, pela alimentação, sanidade e assistência técnica dos 
mesmos, enquanto que o suinocultor dispõe da mão de obra, da infraestrutura e manutenção dos pavilhões de criação. Para os casos que não há o contrato de comodato, o suinocultor é responsável por todo o processo, atuando de forma independente, em muitos casos ele possui uma garantia de venda de seus suínos, porém todos os dispêndios do processo são de sua responsabilidade.

Nota-se que os modelos de UPLD e UPLD Comodato possuem as mesmas características, ou seja, em ambos os casos ocorre a fase inicial do processo. Os suínos permanecem na propriedade por um período que compreende do seu nascimento até aproximadamente 28 dias, quando chegam a um peso médio de 7,5Kg. Porém, na UPLD a atividade é desenvolvida sob a responsabilidade exclusiva do suinocultor, enquanto que na UPLD Comodato, ocorre a divisão de responsabilidades entre o suinocultor e uma determinada empresa.

Após a conclusão da etapa das UPLDs, os suínos são transferidos para a UPLC, também conhecidas como crechários. Nesta etapa, os suínos permanecem por aproximadamente 35 dias e chegam ao peso médio de $23 \mathrm{Kg}$. Esta parte do processo é desenvolvida pelo sistema de contrato de comodato.

Os modelos denominados UPL e UPL Comodato compreendem um processo que corresponde às etapas da UPLD mais a UPLC juntas, ou seja, é um processo em que os suínos permanecem no estabelecimento do seu nascimento até atingirem em média $23 \mathrm{Kg}$ de peso, com idade aproximada de 63 dias. No entanto, aos 28 dias de vida eles são separados das matrizes até atingirem o final deste processo. Existem UPLs que desenvolvem a atividade de forma independente, sem comodato e também as que atuam sob a forma de comodato com as empresas.

A modalidade denominada UT representa a fase de terminação dos suínos. Esta etapa agrega os suínos que passaram pelas UPLs ou pelas UPLCs, chegam com aproximadamente 63 dias de vida, pesando $23 \mathrm{Kg}$ e permanecem na propriedade em média mais 118 dias e atingem um peso final de $120 \mathrm{Kg}$. Ao atingirem esta idade e peso estão prontos para o abate e industrialização. A terminação dos suínos é desenvolvida por meio de comodato entre suinocultores e empresas. Existem também 
suinocultores que desenvolvem todo o processo de forma independente. Estes assumem todos os custos do processo e não possuem vínculo com empresas, de modo que precisam comercializar seu produto no mercado e estão sujeitos aos riscos da demanda.

A Tabela 1 apresenta os custos de produção em cada uma das modalidades de produção. Destaca-se que são aqui considerados apenas os custos de cada modalidade, sem considerar o custo agregado na modalidade anterior, para isso há um demonstrativo na Tabela 1.

Tabela 1: Custos dos sistemas de produção de suínos

\begin{tabular}{|c|c|c|c|c|c|c|}
\hline Modalidade/etapa & Custos e peso & 10 Trim. & 2o Trim. & 3으. Trim. & 4음im. & Média \\
\hline \multirow{5}{*}{ UPLD } & $\begin{array}{c}\text { Custo do produtor / } \\
\mathrm{Kg}\end{array}$ & 9,76 & 9,66 & 9,25 & 9,28 & 9,49 \\
\hline & $\begin{array}{l}\text { Custo da indústria } \\
\text { / Kg }\end{array}$ & 0,00 & 0,00 & 0,00 & 0,00 & 0,00 \\
\hline & Custo total / Kg & 9,76 & 9,66 & 9,25 & 9,28 & 9,49 \\
\hline & $\begin{array}{l}\text { Peso médio } \\
\text { agregado }\end{array}$ & 7,50 & 7,50 & 7,50 & 7,50 & 7,50 \\
\hline & $\begin{array}{l}\text { Custo total do } \\
\text { suíno }\end{array}$ & 73,22 & 72,51 & 69,41 & 69,65 & 71,20 \\
\hline \multirow{5}{*}{ UPLD Comodato } & $\begin{array}{c}\text { Custo do produtor / } \\
\mathrm{Kg}\end{array}$ & 2,64 & 2,63 & 2,63 & 2,63 & 2,63 \\
\hline & $\begin{array}{l}\text { Custo da indústria } \\
\text { / Kg }\end{array}$ & 6,71 & 6,65 & 6,36 & 6,36 & 6,57 \\
\hline & Custo total / Kg & 9,35 & 9,28 & 8,99 & 9,00 & 9,15 \\
\hline & $\begin{array}{l}\text { Peso médio } \\
\text { agregado }\end{array}$ & 7,50 & 7,50 & 7,50 & 7,50 & 7,50 \\
\hline & $\begin{array}{l}\text { Custo total do } \\
\text { suíno }\end{array}$ & 70,13 & 69,65 & 67,45 & 67,55 & 68,69 \\
\hline \multirow{5}{*}{ UPLC Comodato } & $\begin{array}{c}\text { Custo do produtor / } \\
\text { Kg }\end{array}$ & 0,28 & 0,25 & 0,24 & 0.24 & 0,25 \\
\hline & $\begin{array}{l}\text { Custo da indústria } \\
\text { / Kg }\end{array}$ & 1,99 & 1,97 & 2,05 & 2,34 & 2,09 \\
\hline & Custo total / Kg & 2,27 & 2,22 & 2,29 & 2,58 & 2,34 \\
\hline & $\begin{array}{l}\text { Peso médio } \\
\text { agregado }\end{array}$ & 15,50 & 15,50 & 15,50 & 15,50 & 15,50 \\
\hline & $\begin{array}{l}\text { Custo total do } \\
\text { suíno }\end{array}$ & 35,25 & 34,47 & 35,60 & 40,07 & 36,34 \\
\hline \multirow{2}{*}{ UPL } & $\begin{array}{c}\text { Custo do produtor / } \\
\mathrm{Kg}\end{array}$ & 4,79 & 4,79 & 4,70 & 4,71 & 4,76 \\
\hline & $\begin{array}{l}\text { Custo da indústria } \\
\text { / Kg }\end{array}$ & 0,00 & 0,00 & 0,00 & 0,00 & 0,00 \\
\hline
\end{tabular}


Análise comparativa dos custos de produção de suínos sob a ótica da teoria contratual Leandro Augusto Toigo, Vanderlei Gollo, Maurício Leite, Roberto Carlos Klann

\begin{tabular}{|c|c|c|c|c|c|c|}
\hline & Custo total / Kg & 4,79 & 4,79 & 4,70 & 4,71 & 4,75 \\
\hline & $\begin{array}{l}\text { Peso médio } \\
\text { agregado }\end{array}$ & 23,00 & 23,00 & 23,00 & 23,00 & 23,00 \\
\hline & $\begin{array}{l}\text { Custo total do } \\
\text { suíno }\end{array}$ & 110,17 & 110,17 & 108,19 & 108,43 & 109,24 \\
\hline \multirow{5}{*}{ UPL Comodato } & $\begin{array}{c}\text { Custo do produtor / } \\
\mathrm{Kg}\end{array}$ & 1,01 & 0,97 & 0,96 & 0,96 & 0,98 \\
\hline & $\begin{array}{l}\text { Custo da indústria } \\
\text { / Kg }\end{array}$ & 3,63 & 3,65 & 3,59 & 3,57 & 3,61 \\
\hline & Custo total / Kg & 4,64 & 4,63 & 4,56 & 4,57 & 4,60 \\
\hline & $\begin{array}{l}\text { Peso médio } \\
\text { agregado }\end{array}$ & 23,00 & 23,00 & 23,00 & 23,00 & 23,00 \\
\hline & $\begin{array}{c}\text { Custo total do } \\
\text { suíno }\end{array}$ & 106,84 & 106,61 & 104,88 & 105,18 & 105,87 \\
\hline \multirow{5}{*}{ UT Comodato } & $\begin{array}{c}\text { Custo do produtor / } \\
\text { Kg }\end{array}$ & 0,19 & 0,19 & 0,19 & 0,19 & 0,19 \\
\hline & $\begin{array}{l}\text { Custo da indústria } \\
\text { / Kg }\end{array}$ & 1,80 & 1,69 & 1,80 & 1,95 & 1,81 \\
\hline & Custo total / Kg & 2,00 & 1,88 & 2,00 & 2,14 & 2,00 \\
\hline & $\begin{array}{l}\text { Peso médio } \\
\text { agregado }\end{array}$ & 97,00 & 97,00 & 97,00 & 97,00 & 97,00 \\
\hline & $\begin{array}{l}\text { Custo total do } \\
\text { suíno }\end{array}$ & 194,00 & 182,75 & 194,00 & 208,26 & 194,75 \\
\hline \multirow{5}{*}{ Ciclo Completo } & $\begin{array}{c}\text { Custo do produtor / } \\
\mathrm{Kg}\end{array}$ & 2,83 & 2,77 & 2,88 & 3,02 & 2,88 \\
\hline & $\begin{array}{l}\text { Custo da indústria } \\
\text { / Kg }\end{array}$ & 0,00 & 0,00 & 0,00 & 0,00 & 0,00 \\
\hline & Custo total / Kg & 2,83 & 2,77 & 2,88 & 3,02 & 2,88 \\
\hline & $\begin{array}{l}\text { Peso médio } \\
\text { agregado }\end{array}$ & 110,00 & 110,00 & 110,00 & 110,00 & 110,00 \\
\hline & $\begin{array}{c}\text { Custo total do } \\
\text { suíno }\end{array}$ & 312,29 & 305,03 & 317,24 & 332,53 & 316,80 \\
\hline
\end{tabular}

Fonte: Dados da pesquisa

Observa-se na Tabela 1, o valor dos custos em cada uma das etapas do processo, bem como dos diferentes cenários de produção. Estão representados os custos que pertencem ao suinocultor e a indústria (empresa), demonstrando desta maneira o quanto do custo é de responsabilidade de cada uma das partes envolvidas.

Os valores dos custos nos cenários de UPLDs levam em consideração uma estrutura com 350 matrizes no processo produtivo. Para os cenários que operam na forma de UPLs estes custos também forma calculados considerando uma estrutura com 350 matrizes em produção. No processo do ciclo completo os custos foram calculados considerando uma estrutura com 180 matrizes. 
Os sistemas de UPLCs e UTs não possuem matrizes de reprodução e para cálculo de custos destes modelos considerou-se uma estrutura com 400 suínos por lote nas UPLCs e com 265 suínos nas UTs. Os custos são demonstrados trimestralmente, bem como a sua média para todo o período.

Ao analisar as UPLDs com as UPLDs Comodato e as UPLs com as UPLs Comodato, modalidades que possuem os cenários de comodato e também desenvolvida de forma independente, percebe-se que onde há o cenário de comodato o custo final do suíno naquela etapa é menos que o sistema independente. Buscando identificar qual o cenário que apresenta o menor custo de produção na suinocultura catarinense foi agregado as diferentes etapas, conforme apresentado na Tabela 2.

Tabela 2: Custos nos diferentes cenários da suinocultura

\begin{tabular}{|l|c|c|c|c|c|c|c|c|}
\hline Cenários & Descrição & $\begin{array}{c}\text { Número } \\
\text { de dias }\end{array}$ & $\begin{array}{l}\text { Peso } \\
\text { final }\end{array}$ & 10 Trim. & 2o Trim. & 3o Trim. & 4 Trim. & Média \\
\hline Cenário 1 & $\begin{array}{c}\text { UPLD + UPLC } \\
\text { Comodato+ UT } \\
\text { Comodato }\end{array}$ & 181 & 120 & 302,47 & 289,73 & 299,02 & 318,38 & 302,40 \\
\hline Cenário 2 & $\begin{array}{c}\text { UPLD Comodato + } \\
\text { UPLC Comodato + UT } \\
\text { Comodato }\end{array}$ & 181 & 120 & 299,37 & 286,87 & 297,05 & 316,28 & 299,89 \\
\hline Cenário 3 & UPL + UT Comodato & 181 & 120 & 304,17 & 292,92 & 302,19 & 316,69 & 303,99 \\
\hline Cenário 4 & $\begin{array}{c}\text { UPL Comodato + UT } \\
\text { Comodato }\end{array}$ & 181 & 120 & 300,84 & 289,35 & 298,88 & 313,44 & 300,62 \\
\hline Cenário 5 & Ciclo Completo & 163 & 110 & 312,29 & 305,03 & 317,24 & 332,53 & 316,77 \\
\hline
\end{tabular}

Fonte: Dados da pesquisa

Após terem sido encontrados os custos de produção de cada um dos processos e etapas foram encontrados os custos em cada um dos cenários apresentados na Figura1. É possível, desta maneira, observar qual dos modelos apresenta menor custo de produção na cadeia da suinocultura. A partir da análise dos valores constantes na Tabela 2, nota-se o comportamento dos custos trimestralmente, assim como a média de todo o período analisado. 
Nos primeiros quatro cenários, o melhor resultado, ou seja, o menor custo apresentado compreende ao segundo trimestre de 2013, sendo que o terceiro trimestre apresentou o segundo menor custo e o quarto trimestre o maior custo do período. No entanto, no cenário de ciclo completo, nota-se o menor custo também no segundo trimestre, mas seguidos pelo primeiro, terceiro e quarto trimestres de 2013.

Estão apresentados também a quantidade média de dias necessários para finalização do processo, bem como o peso final dos suínos. Para os quatro primeiros cenários há uma igualdade no tempo de vida e peso dos suínos, em todos os casos, para que os suínos atinjam $120 \mathrm{~kg}$ (em média) são necessários 181 dias (em média). No entanto o quinto cenário considera um período de 163 dias para um peso final de 110 kg por suíno (em média).

O cenário 2 (UPLD Comodato + UPLC Comodato + UT Comodato) é o que apresenta menor custo de produção, com custo médio de $R \$ 299,89$ por suíno. O segundo melhor cenário é o 4 (UPL Comodato + UT Comodato) com custo médio de R $\$$ 300,62 por suíno. Na terceira colocação aprece o cenário 1(UPLD + UPLC Comodato + UT Comodato) com custo médio de R $\$ 302,40$ por suíno, seguido pelo cenário 3 (UPL + UT Comodato) com custo médio de $\mathrm{R} \$ 303,99$ por suíno. No entanto, o cenário 5 que representa o ciclo completo, apesar de um tempo menor para a finalização do processo (163 dias) e um peso final dos suínos também menor $(110 \mathrm{Kg}$ ), apresenta o maior custo de todos os cenários com o equivalente a $R \$ 316,77$ por animal.

\section{CONCLUSÕES}

Com o objetivo de analisar os custos das diferentes modalidades de produção na cadeia da suinocultura catarinense, buscou-se a partir de informações disponibilizadas pela CONAB elaborar os possíveis cenários existentes na cadeia de produção de suínos.

A suinocultura catarinense é desenvolvida basicamente sob duas subdivisões das modalidades de produção: um cenário com contrato de comodato entre empresas e 
suinocultores e outro cenário com suinocultores independente, em que não há a presença de comodato entre as partes e os suinocultores mantém-se na atividade com recursos financeiros próprios.

Os resultados apontaram para custos menores quando há a presença de contratos de comodato, como pode ser observado nas UPLDs e UPLs, modalidades onde a atividade desenvolve-se sob os dois aspectos. Para as modalidades de UPLCs e UTsnão é possível fazer este tipo de comparação, pela existência de informações apenas sob o modelo de comodato para estas modalidades de produção. Neste mesmo sentido, o para a modalidade de ciclo completo não há o cenário de contrato de comodato, apenas o suinocultor independente impossibilitando a comparação.

Entretanto, com a finalidade de encontrar a modalidade que representa o menor custo foram estabelecidos os cenários na produção de suínos. Desta maneira, a partir dos resultados obtidos, percebeu-se os cenários com contratos de comodato como os melhores quando se refere ao montante de custos de produção, pois o cenário de ciclo completo apresentou um custo mais elevado mesmo com período e peso dos suínos menores que os demais modelos.

Como sugestão de futuras pesquisas recomenda-se a elaboração de estudos que possibilitem analisar qual dos cenários apresenta o melhor retorno para os suinocultores e para a empresa. Outra possibilidade é comparar os custos da suinocultura catarinense com os demais estados, bem como, com o cenário nacional, a fim de identificar os fatores causadores das possíveis variações nos custos entre as regiões.

\section{REFERÊNCIAS}

AGUIAR, A. B.; ROCHA, W. Uma análise da complementaridade entre gestão interorganizacional de custos e open-book accounting. 7. Congresso USP de Controladoria e Contabilidade. São Paulo, 2007.15 p.

ANAND, M. A review of research on the theory \& practice of cost management. South Asian Journal of Management. Vol.11, N. 1, p. 59-98, Jan.-Mar, 2004. 
ANDERSON, S. W. Managing costs and cost structure throughout the value chain: research on strategic cost management. In Chapman, C.; Hopwood, A.; Shields, M. (editor). Handbook of Management Accounting Research. Vol 2. Oxford: Elsevier, 2006.

ASSOCIAÇÃO CATARINENSE DE CRIADORES DE SUÍNOS - ACCS. Histórico da suinocultura, (2008). Disponível em: http://www.accs.org.br/dados_ver.php?id=2. Acesso em: 01 de agosto de 2013.

BACIC, M. J. (1994). Escopo da gestão estratégica de custos em face das noções de competitividade e de estratégia empresarial. Congresso Brasileiro de Gestão Estratégica de Custos. 1. São Leopoldo, Unisinos.

BOWERSOX, D. J.; CLOSS, D. J. (1996). Logistical management: the integrated supply chain process. New York: McGraw-Hill, 730 p.

COASE, R. H. (1937). The nature of the firm. Economica, v. 4, n. 16, p. 386-405.

COASE, R. Harry. (1960). Problem of Social Cost, The. JL \& econ., v. 3, p. 1

COOPER, R.; SLAGMULDER, R. (2004). Cost analysis outside the organization. Cost Management. Vol.18, Iss. 3. Boston: May/Jun. 3 p.

COOPER, R.; SLAGMULDER, R. (2003). Strategic cost management: expanding scope and boundairies. Cost Management. Vol. 17, Iss. 1. Boston: Jan/Fev. 8 p.

COOPER, R.; SLAGMULDER, R. Suplly chain management for lean enterprise: interorganizational cost management. Strategic Finance. Vol. 80. Iss. 10. Apr/1998. p. 15-16.

DALMACIO, F. Z.; REZENDE, A. J. A (2008). Relação entre o Timeliness e a Utilidade da Informação Contábil e os Mecanismos de Governança Corporativa: Evidencias no Mercado Acionário Brasileiro. Revista de Administração e Contabilidade da Unisinos. v. 5, n. 3, p. 163-174, set./dez.

DIEHL, C. A. (2004). Controle estratégico de custos: um modelo referencial avançado. 2004. 306 f. Tese (Doutorado em Engenharia da Produção) - Programa de Pós Graduaçãoem Engenharia da Produção. Universidade Federal de Santa Catarina, Florianópolis.

DIEHL, C. A. (1997). Proposta de um sistema de avaliação de custos intangíveis. Dissertação (Mestrado em Engenharia de Produção) - Universidade Federal do Rio Grande do Sul - UFRGS, Porto Alegre. 
EL-DYASTY, M. M. (2007). A framework to accomplish strategic cost management. Social Science Research Network. 63 p. Disponível em: http://ssrn.com/abstract=704201 Acesso em: 28 de dezembro de 2008.

EL-KELETY, I. A. E. M. (2006). Towards a conceptual framework for strategic cost management: the concept, objective, and instruments. 2006. 556 f. Dissertação. Chemnitz University of Technology, Chemnitz.

ELLRAM, L. M.; SIFERD, S. P. (1993). Purchasing: the cornestone of the total cost of ownership. Journal of Business Logistics. Vol. 14 p. 163-185.

ELLRAM, L. M. The implementation of target costing in the United States: theory versus practice. Journal of Supply Chain Management. Vol. 42. 2006. p. 13-26

FU, Y. Strategic cost management in chain. Asian-Pasific Management Journal, Selangor, v.2, n.1, p.89-119.

HEADY, E. O.; DILLON, J. L. (1961). Agricultural Production Functions. Ames. lowa State University, p. 667.

KEY, N.; MCBRIDE, W. D. (2003). Production contracts and productivity in the U.S. hog sector. American Journal of Agricultural Economics, v. 85, n.1, p.121-133.

LOCKAMY III, A. (2003). A constraint-based framework for strategic cost management. Industrial Management + Data Systems. Wembley. Vol. 103, Issue 8/9, p. 591-599.

LOPES, A. B.; IUDÍCIBUS, S. (Coord.). (2012). Teoria avançada da contabilidade. 2. ed. São Paulo: Atlas.

LOPES, M. Uma agenda para a suinocultura brasileira. (2013). Disponível em: http://blogs.ruralbr.com.br/suinoculturabrasileira/. Acesso em: 05/ago/2013.

MCDONALD, James, PERRY, Janet; AHEARM, Mary; BANKER, David; CHAMBERS, William; DIMITRI, Carolyn; KEY, Nigel; NELSON, Kenneth; SOUTHARD, Leland. (2004). Contracts, Markets, and Prices: Organizing the Production and Use of Agricultural Commodities. USDA EconomicResearch Service. Agricultural Economic Report.

MIELE, M.; MACHADO, J. S. (2010). Panorama da carne suína brasileira. Disponível em: http://www.agroanalysis.com.br/especiais_detalhe.php?idEspecial=54. Acesso em: 01 de agosto de 2013. 
MIELE, M. (2006). Contratos, especialização, escala de produção e potencial poluidor na suinocultura de Santa Catarina. 278 f. (Tese de Doutorado). Programa de PósGraduação em Agronegócios da Universidade Federal do Rio Grande do Sul. Porto Alegre.

MINISTÉRIO DA AGRICULTURA PECUÁRIA E ABASTECIMENTO - MAPA. Suínos. Disponível em: <http://www.agricultura.gov.br/animal/especies/suinos>. Acesso em: 01 de agosto de 2013.

NAKAGAWA, M. (1994). ABC - Custeio baseado em atividades. São Paulo: Atlas.

NAKAGAWA, M. (1991). Gestão estratégica de custos. São Paulo: Atlas, 111 p.

NOGUEIRA, M. P. (2004). Gestão de custos e avaliação de resultados: Agricultura e pecuária. Bebedouro: Scott.

PORTER, M. (1989). Vantagem competitiva: criando e sustentando um desempenho superior. Tradução Elizabeth Maria de Pinho Braga. 24. ed. Rio de Janeiro: Campus. $512 \mathrm{p}$.

ROCHA, W. (1999). Contribuição ao estudo de um modelo conceitual de sistema de informação de gestão estratégica.158 f. Tese de Doutorado. Faculdade de Economia, Administração e Contabilidade da Universidade de São Paulo, São Paulo.

ROPPA, L. (2012). A crise da suinocultura brasileira. Disponível em: http://www.emater.go.gov.br/w/4307. Acesso em: 04 de agosto de 2013.

SECRETARIA DE ESTADO DA AGRICULTURA E DO ABASTECIMENTO (2013). Suinocultura - análise da conjuntura agropecuária. Disponível em: http://www.agricultura.pr.gov.br/arquivos/File/deral/Prognosticos/SuinoCultura_2012_20 13.pdf. Acesso em: 01 de agosto de 2013.

SHANK, J. K.; GOVINDARAJAN, V. (2000). A revolução dos custos: como reinventar e redefinir sua estratégia de custos para vencer em mercados crescentemente competitivos. Tradução Luiz Orlando Lemos. 6 ed. Rio de Janeiro: Campus, 341 p.

SORNBERGER, G. P.; NANTES, J. F. D. (2011). Mensuração e controle dos custos na cadeia interna de valor: um estudo de caso na suinocultura da região norte de Mato Grosso, Revista Informações Econômica, v.41, n.7, Jul.11, São Paulo.

SOUZA, B. C.; ROCHA, W. (2008). Fatores condicionantes da gestão de custos interorganizacionais. 8. Congresso USP de Controladoria e Contabilidade. São Paulo. 
TIGRE, P. B. (1998). Inovação e teorias da firma em três paradigmas. Revista de economia contemporânea, v. 3, p. 67-111.

WEYDMANN, C. L.; CONCEIÇÃO, A. Comparação da produção potencial de dejetos na produção suinícola integrada e independente em Santa Catarina. In: CONGRESSO BRASILEIRO DE ECONOMIA E SOCIOLO-GIA RURAL, 41, 2003, Juiz de Fora. Anais... Brasília: SOBER, 2003. CD-ROM.

WRUBEL, F.; DIEHL, C. A.; TOIGO, L. A.; OTT, E. Uma proposta para a validação de categorias sobre gestão estratégica de custos. Revista Brasileira de Gestão de Negócios, v. 13, n. 40, p. 332-348, 2011.

WRUBEL, F. (2009). Informações sobre gestão estratégica de custos divulgadas por companhias abertas brasileiras. 145 f. (Dissertação de Mestrado). Curso de PósGraduação em Ciências Contábeis, Universidade do Vale do Rio dos Sinos, São Leopoldo.

ZANIN, A.; BAGATINI, F. M.; PESSATTO, C. B. (2010). Viabilidade econômicofinanceira de implantação de biodigestor: uma alternativa para reduzir os impactos ambientais causados pela suinocultura.Custos e @gronegócioonline, v. 6, n. 1.

ZYLBERSZTAJN, D. (2005). Papel dos contratos na coordenação agroindustrial: um olhar além dos mercados. Revista de Economia e Sociologia Rural, v. 43, n. 3, p. 385420.

Data de Submissão: 28/02/2015

Data de Aceite: 12/02/2016 